Adipositas

\section{Einfluss von subkutanem Fettgewebe auf kardiometabolische Risikofaktoren}

Hintergrund: Während viszerales Fettgewebe ein anerkannter Risikofaktor für metabolische und kardiovaskuläre Erkrankungen ist, bleibt die Bedeutung subkutanen Fettgewebes umstritten.

Methoden: Im Rahmen der Offspring und 3. Generation Framingham Heart Study wurden 3001 Teilnehmer (48,5\% Frauen) nach Geschlechter getrennt anhand ihres viszeralen Fettgewebes (visceral adipose tissue = VAT) in niedrige, mittlere und obere Tertilen eingeteilt. Innerhalb der Tertilen wurde altersadaptiert der Zusammenhang zwischen den Tertilen für das subkutane Fettgewebe im Bereich des Abdomens (subcutaneous adipose tissue $=$ SAT) und kardiometabolischen Risikofaktoren untersucht. VAT und SAT waren zuvor mittels AbdomenComputertomografie ermittelt worden. Ergebnisse: In der Gruppe der niedrigen VAT-Tertile war die Prävalenz der Risi-

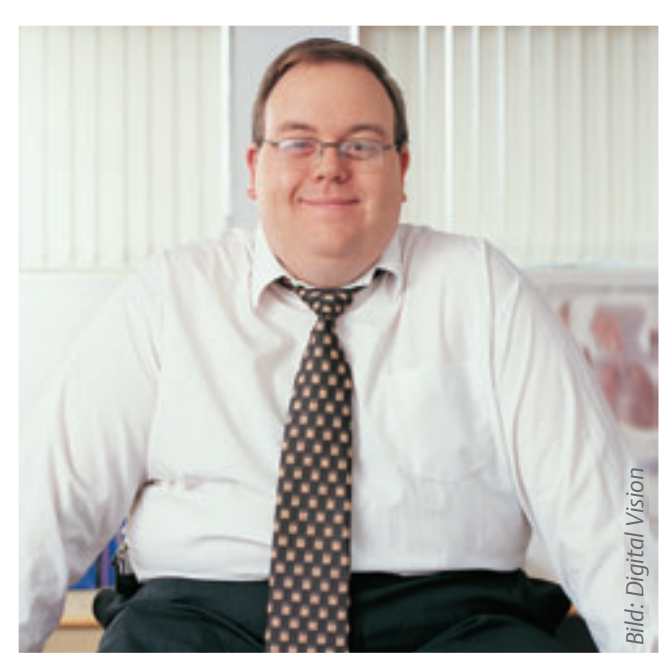

kofaktoren niedrig und es fand sich ein signifikanter Zusammenhang zwischen ansteigenden SAT-Tertilen und zahlreichen der untersuchten Risikofaktoren (Hypertriglyzeridämie, Nüchtern-Blutglukose, Hypertonus, metabolisches Syndrom). Im Gegensatz dazu waren in der Gruppe der hohen VAT-Tertile alle Risikofaktoren häufiger und eine eindeutige Assoziation zwischen SAT-Tertilen und Risikofaktoren wie beispielsweise HDL-Cholesterin oder Blutglukosewerten konnte nicht festgestellt werden. Die

Triglyzeride lagen sogar mit steigenden SAT-Tertilen niedriger (Männer; $64,4 \%$ erhöhte Triglyzeride in der SAT-Tertile 1 vs. $52,7 \%$ SAT-Tertile 3). Bei Frauen waren die Ergebnisse ähnlich, wenngleich nicht signifikant (50,6\% erhöhte Triglyzeride in der SAT-Tertile 1 vs. 40,1\% SAT-Tertile 3). Fazit: Abdominelles Fettgewebe erhöht die Prävalenz metabolischer und kardiovaskulärer Risikofaktoren. Demgegenüber ist subkutanes Fettgewebe - zumindest bei gleichzeitig vermehrtem viszeralen Fettgewebe - kein eigenständiger Risikofaktor für metabolische und kardiovaskuläre Erkrankungen. Im Gegenteil scheint bei Adipositas und Hypertriglyzeridämie subkutanes Fettgewebe einen protektiven Effekt zu haben, so die Autoren. Dr. med. Winfried Keuthage, Münster

Quelle: Porter S, Massaro JM, Hoffmann U et al. Abdominal subcutaneous adipose tissue: a protective fat depot? Diabetes Care 2009; 32: 1086-1075 